\title{
The Choice between Train and Bus in Durres-Tirana Axis
}

\author{
Alush Kuci \\ University "Aleksander Moisiu" Durres, Albania \\ E-mail: alush.kuci@yahoo.com
}

\section{Doi:10.5901.ajis/2013.v2n4p143}

\section{Abstract:}

The Tirana-Durres axis, due to democratic development of the last two decades, represents the richest markets in the Albania's transportation industry. Internal migrations from rural areas and demographic developments during that period have made this part of the nation's home of approximately half of country's population. The commercial and residential buildings are extended along the entire distance between Tirana and Durres, the two largest cities of the country, which actually belong to a unified urban centre. However, despite the construction of a highway just a decade ago and the restructuring of some auxiliary roads, the congestion, the flow of passengers and merchandise, and pollution in this axis has become a great concern. Parallel to the highway runs the railway line, which serves passangers moving between Tirana and Durres. For several reasons, ranging from type of trains to investments, the rail system is neglected. Passenger market share of this axis covered by the railway represents only $0.02 \%$ of the total demand. In our opinion the solution is correlated to the integrated transport system and one of its goals is dropping the number of vehicles on the roads at the expense of public transportation. Nevertheless, such an aim requires selecting the type of transport with greatest potential. Therefore, a cost-benefit analysis with a wide spectrum of socioeconomic elements is needed. We believe that this scrutiny, which in this paper is treated in the form of a comparison between the rail system and buses, is the proper way to evaluate motor vehicle and a train transport passenger service on Durres-Tirana axis and to choose the best one. In our model we want to stresses the importance of introducing in the Durres-Tirana railway axis new equipment such as diesel multiple units (DMU). These devises serve simultaneously as a locomotive and as a railroad car. Many European countries use DMU in short lines. In such a conception, DMU service extension can serve in Durres-Tirana transport perspective and later on in a gradual expansion in other segments of the Albanian Railway Network.

Key words: Tirana-Durres axis, cost-benefit analysis, DMU (diesel multiple unit), and integrated transport.

The analysis for choosing between train and bus passenger transport service in Durres-Tirana axis does not imply a decision serving business interests, but an appraisal of a larger socioeconomic problem in the context of an integrated transport system. Continuing to deal with such a problem only from the investment-in-roads point of view, it means ignoring the external costs related to environmental pollution and roads phenomena. The experience of many European countries will be very helpful at this point of our analysis. To paraphrase Affuso, Masson, and Newberry, there is a further worry that if the major benefits justifying subside to private sector rail investment are reductions in road congestion, than it needs to be demonstrated that it is more cost - effective to allocate funds to rail to reduce the road congestion rather than directly to road investment to relieve constraints. ${ }^{1}$

During the communism socioeconomic system, where the means of production were socially-owned, the rail was considered the optimal transportation in all extent parallel to the railway line. After 1992 the liberalization of the transport market gave a powerful boost to passenger transport service on the road. Buses

1 Luisa Affuso, Julien Masson, and David Newbery. Comparing Investment on new transport infrastructure. Roads vs. Railways? Department of Applied Economics, University of Cambridge, b. Ecole Politechnique. First Draft: November 2000. This draft: July 2003. 
and minivans were dispersed across the country's road network, taking over the public transport service. In such a situation of competition, rail transport began to lose significant part of its volume.

The Tirana Durres highway and a new auxiliary renovated roads system have improved greatly the communication among several cities. The railway line, which enables freight and passenger transportation in the area, has made its part. However, during the last two decades the railway transport volume indicators have declined and rail transport is left behind, including the Durres-Tirana railway axes. As if this is not enough, the flow of vehicles along the highway and particularly in the entrance of the two cities is enormous and environmental pollution and congestions have become an everyday concern. There is evidence that road investment cannot solve these problems. In our judgment, such a situation requires a new strategy which implies the beginning of integrated transport in the Durres-Tirana axis and a crucial part of this master plan is a new concept of railway transportation. In a parallel lane with the railway runs a motor vehicle transportation system, which offers a different passenger service. This coincidence facilitates the comparison of alternatives and decision-making.

\section{Some of the train priorities compared to bus}

1. The train can attain higher technical speeds and therefore smaller travel time. This is made possible due to avoiding road blocking and velocity restrictions. These factors become even more evident in urban areas.

2. Due to the greater capacity of a railway carriage, trains can carry a greater number of passengers in the same amount of time. Secondly, we can increase the number of carriages to fit the demand of passengers during rush hours, holidays, and peak seasons, which cannot be applied on motor vehicle transportation. This means trains can use the rail line much more efficiently in comparison with buses in relation to a road.

3. Theoretically we can increase the capacity of the bus system by setting several buses in line, which requires more parking lots in cities, let alone the increasing number of bus drivers.

4. Trains require less mobility space compared to buses because they move on the narrow path between two rails and it don't stop to yield other means of transportation. Thus, especially during rush hours and at peak periods, railway transportation helps to avoid the traffic jam.

5. Trains tend to realize smaller operating cost per passenger kilometre compared to the buses. This is linked to the fact that railway vehicles transport more passengers, because of the greater space available to them.

6. Trains bear some other tangible and intangible advantages. They are safer. They run on a wellprécised path and only in one direction. Therefore the chances for accidents are much smaller than on buses, which operate among hundred drivers not always well-qualified and running not at all times on the same direction.

- Trains are reliable. Its punctuality comes from the ability to follow scheduled travel time by avoiding unexpected traffic congestions, accidents, and more.

- Trains are more comfortable than buses. The comfort during commuting is linked with better conditions during trains' travel, with larger spaces and without strong curves et cetera.

\section{Type of train to be used}

Passenger trains that move in the Albanian railway network are pulled by locomotives CKD at 1350 horse power. This type of locomotive is designed for the movement and handling of heavy goods trains on the 
shunting stations. It produces very high operating costs, low velocity, and low acceleration. ${ }^{2}$ In contrast to these traditional trains, DMUs are self-propelled motorized units that resemble a bus running on rails. One or more of DMUs put together set up a train, making possible the adjustment of its capacity with the demand for transport ${ }^{3}$. This is because with the increase or decrease of DMUs as part of the train, it augments or it reduces its carrying capacity and propelling power as well. Because of the above properties and easier construction compared to traditional trains, the DMUs are very interesting for the present situation of the Tirana-Durres axis. Moreover, it makes the bus obsolete: the buses are parked by railway stations on both cities. Being parallel services and shearing a common corridor, they will be considered mutually exclusive.

\section{Model used to perform cost-benefit analysis}

The model used for the development of socioeconomic analysis on the Tirana-Durres axis is an adaptation of a stylised cost -benefit analysis model ${ }^{4}$ for the choice between the bus and light train. The suitable model in general bears parameters and variables of the stylized model with some adjustments in relation to the uniqueness of the problem and the Albanian reality. Adaptation of the model takes into account several phenomena and necessity that are listed as following:

1. The cities of Tirana and Durres, although administratively separated, are going to their territorial unity, so are considered part of the same urban area. This homogenizing trend will continue to remain strong. The Tirana-Durres axis will continue to represent the wealthiest markets in the Albanian economy and migration flows will continue to be significant in the coming years. In this context passenger transport service through highway and railway line parallel to it will be part of a common urban line area.

2. A cost-benefit analysis to choose between the rail system and buses in this case, takes into account the improvement of rail service through a necessary investment and shifting of all traffic volume of buses and minibus services on the rail line.

3. Revenues in passenger transport service with actual trains fail to cover even the cost of fuel or just $25 \%$ of the operating variable costs. A service that creates a loss until not cover variable costs is financially justified to be removed from circulation. ${ }^{5}$ Starting from this principle, the model removes these trains from the Tirana-Durres axis circulation and replaces them with DMU trains.

4. Operation in the Tirana-Durres axis will consider two trains, each outfitted with two DMU units, and departing at the same time in opposite directions, one from Tirana and the other from Durres. Since it is a single railway line, the exchange of trains will be at Vora station, which is located approximately in the middle of the line between two cities. (See diagram 1 and 2)

5. In the analyse we are using to choose between train and bus service, the lasting time of the railway service will be 14 hours a day, which is equal to current bus system. But, due to greater capacity of the trains consisting on two DMU unit (150 seats sitting and 100 standing seats), the frequency of departures will be one train in an hour from each city. (Frequency of the bus system is one bus

2 Current passenger trains that move on Albanian railway network are composed by one, two or three passenger cars. Due to the high operating costs, these trains fail to cover even variable costs in fuel expenditure level. In any view engines CKD $1350 \mathrm{hp}$ can't serve the future development perspective of rail passenger service in the country. Source of data: Directorate General of Albanian Railways.

3 http://en.wikipedia.org/wiki/Diesel-multiple-unit

4 The choice between bus and light rail transit: a stylised cost-benefit analysis model Grimaldi, Raffaele; Laurino, Antonio and Beria, Paolo DiAP - Politecnico di Milano, DiAP - Politecnico di Milano, DiAP - Politecnico di Milano 2010. Online at: http://mpra.ub.uni-muenchen.de/24872/1/MPRA_paper_24872.pdf posted 09. MPRA Paper No. 24872 posted 09. September 2010 / 11:27

5 Stuart Cole. Applied Transport Economics. Policy. Management \& Decision Making. Third Edition, Kogan Page. London and Steering Va. p. 164. 
every 30 minutes.) As a result 14 trains a day will depart from each town or 28 in total, which means half of the bus system movement 6 .

6. The fact that the Durres-Tirana axis will be operated by DMU makes necessary one interchange of trains at Vora and Durres stations for passengers coming from the rest of the railway system, to travel to Tirana and vice versa. (See diagram 2)

\section{Diagram 1}

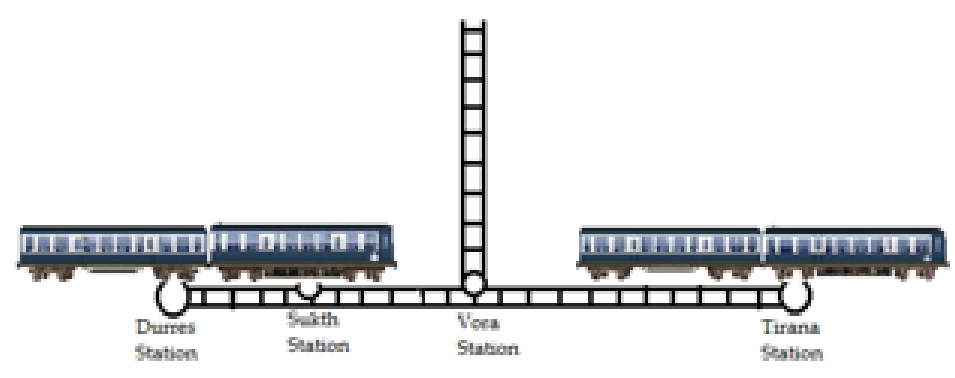

Durres and Vera are exchange stations.

\section{Diagram 2}

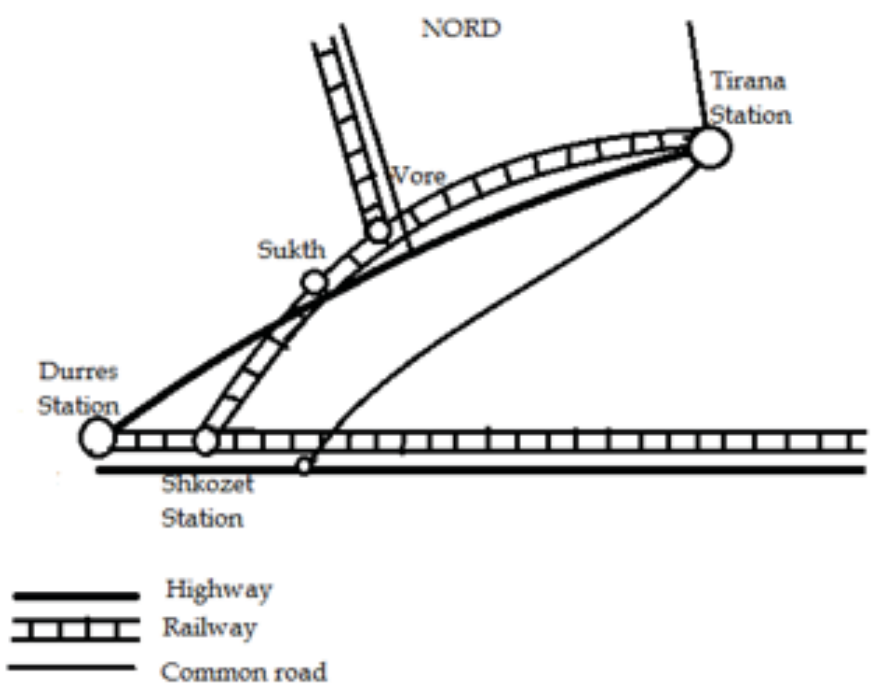

${ }^{6}$ Currently in Durres-Tirana axis move 10 trains per day or 5 trains from each town in opposite directions. 
To describe the level and structure of demand, as the first element of the model, we will present the following parameters.

1. Demand for transport on passenger service in Tirana - Durres-Tirana is shown in the table below:

Table of passengers flow in Durres-Tirana axis for 2011

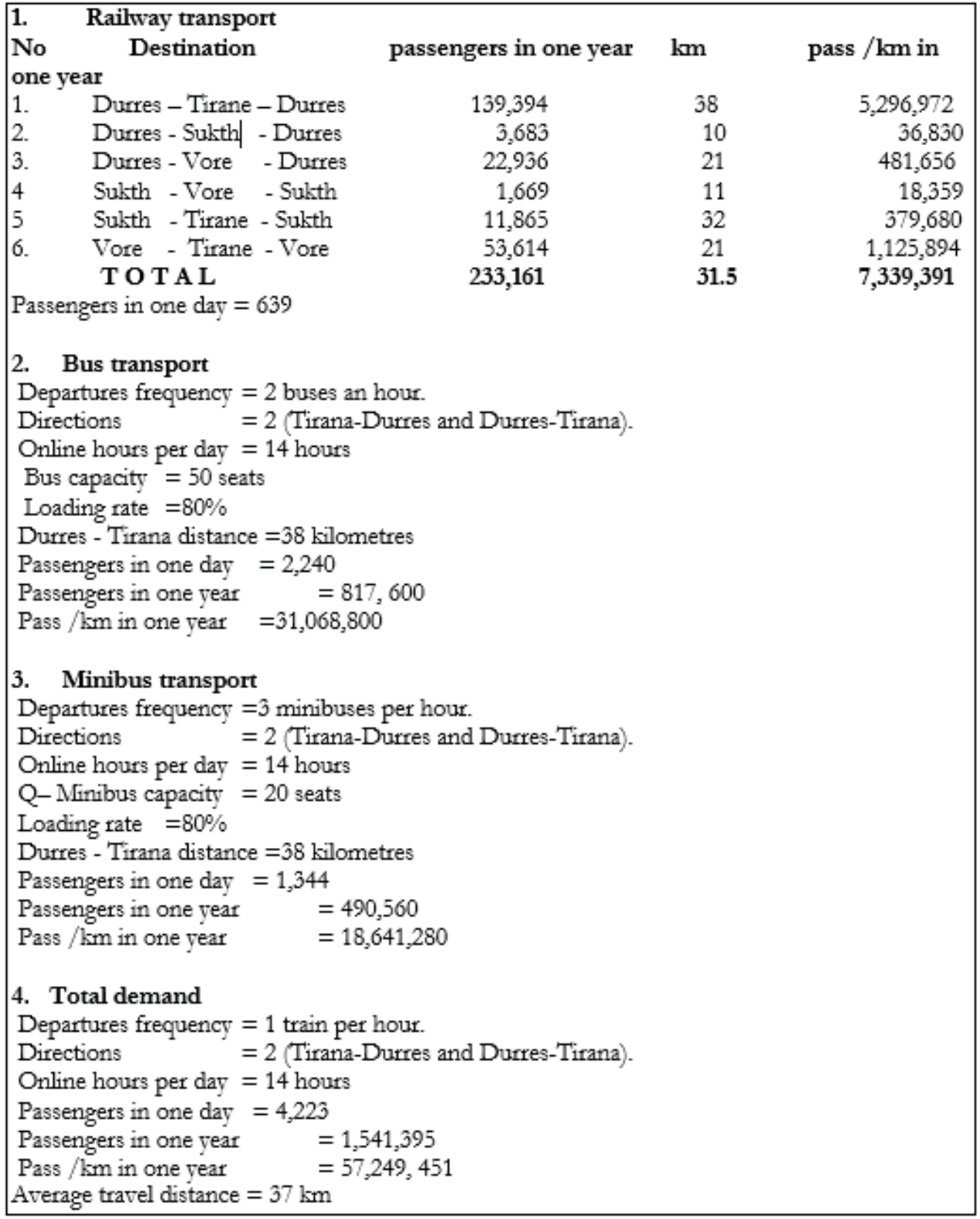


Notes: The data for the volume of traffic to rail system have been taken by the Directorate of passenger transport service in the General Directorate of Albanian Railways. The data for the transport of passengers by busses have been taken by the Municipality of Durres. The data for passenger minivans are the result of observations of the author.

2. The percentage of relative fixed annual demand growth for passenger service transport in TiranaDurres axis is determined to $2 \%$ per year. ${ }^{7}$

3. Coefficient $(f)=0.048$ represents the ratio between passengers who are obliged to exchange train in Durres and Vora station, with the total passengers number annual transport demand (Q.pass) in Tirana - Durres axis.

4. The model takes into account the share of the car traffic volume in the Durres-Tirana axis that with the start of rail service DMU project will be attached to rail transport. This part of the market is forecasted to be equal to a number $(n)=870,000$ passengers per year. 8

\section{Cost of investment}

Tirana-Durres railway segment is an operational line. Although it is designed for speeds of 80 kilometres per hour, currently trains run at speeds up to 60 kilometres per hour. Besides insufficient movement velocity, lines represent many other problems related to signalling systems, traffic control, telecommunication systems, civil construction, illegal overpasses, et cetera. To achieve and control a technical speed of $100 \mathrm{~km}$ per hour, the necessary investment on the railway line and railway vehicles is:

\author{
Signalling System \\ Central traffic control \\ Telecommunications System \\ Project Management \\ Railway lines \\ Civil constructions platform coverings, stations) \\ The wall surrounding 35 kilometre line \\ 4 units DMU vehicles, 2 DMU non-motorized \\ Total \\ Plus 10\% \\ Total investment (I)
}
22,972,867 Euros $^{9}$
1,183,940 Euros
4,630,955 Euros
1,185,348 Euros
13,933,038 Euros
11,011,319 Euros
$11,701,500$ Euros $^{10}$
9,000,000 Euros ${ }^{11}$
75,618,967 Euros
$7,561,896$ Euros
83,180,863 Euros

The residual value of the investment (RV) shall be established for a period $\mathrm{T}=30$ years, equal to $50 \%$ of the initial value of the investment (I), as suggested for railways (MPRA 2010) and updated in the year 0

\footnotetext{
${ }^{7}$ For this parameter it is considered $50 \%$ of the expected average rate of GDP growth in the extent of the investment time of thirty years, $6 \%$ in the first ten years, $4 \%$ in the second ten years and $2 \%$ in the third ten years. $(6+4+2) / 3=4 \times 50 \%=2 \%$ 8 The data are the result of surveys conducted in the city of Tirana and Durres from the author. These observations shows that in an average each of the nearly 20,000 vehicles of Durres realize 5 round trips a year from Durres to Tirana, and 60,000 cars in Tirana realize an average of 9 round trips from Tirana to Durres. According to author observations every car carries an average of 1.7 persons and in $40 \%$ of cases car owners think they would switch from car to train. In other words, this means that a traffic flow of 870,000 commuters or $60 \%$ of total demand (according to the above table) would leave the road and it will be attached to the railway.

${ }^{9}$ Investment required for signalling system, central traffic control, telecommunications systems, project management, and civil construction rail line project are referred to GE Transportation Global Signalling System for renovation of railway axis Tirana - Durres 2005. (Source of data: General Railway Directorate Durres Albania.)

10 Investment for the railway line surrounding wall refers to data of Durres Port Authority costs of construction of the perimeter wall of the port of Durres.

11 Investing for DMU refers to the average price of a unit of about 1.5 million Euros.
} 
before analysis. R-social discount rate $=3.5 \%$ is the recommended value for countries not in cohesion European community (MPRA 2010).

$$
R v=\frac{0,5 \cdot l}{(1+r) T}=0,5 \cdot l \cdot e^{(-r T)}=15129295
$$

\section{Euros}

\section{Operating and maintenance costs}

\section{Maintenance costs}

The model used considers rail system maintenance costs as a fixed cost to a level equal to $1 \%$ of the investment cost for a year. In order to simplify the model, bus system maintenance costs are not taken into account. (MPRA 2010)

Cmbus- cost for the maintenance of the bus line $=0$ Euro /year.

Cmtrain- cost for the maintenance of railway system $=0.01 \cdot 83,180.863$ Euros $=831,808$ Euros $/$ year. While the annual cost $(\mathrm{Cm})$ that will withstand rail system for one year compared with the bus system is: $\mathrm{Cm}=$ Cmtrain - Cmbus $=831,808$ Euros .

\section{Operating costs}

The DMUs operating cost, as required by the model, is expressed in relation to the cost of a bus, which is taken from the stylized model for selection between a train and a bus is 3 Euros per bus kilometre (MAPRA 2010). In conditions of insufficient data due to the lack of previous DMU operating experiences in Albania, operating costs of a bus is defined indirectly in relation to bus costs. Operating cost per passenger kilometre on a bus with 50 seats and an $80 \%$ loading ratio is equal to:

Co.bus. pass $/ \mathrm{km}=3$ Euros $/ 40=0.075$ Euro.

To determine the operating costs for pass / km of DMU's the bus operating cost for pass/ km will multiply with two coefficients as follows:

Co.DMU.pass $/ \mathrm{km}=0.075 \cdot 40 / 30 \cdot 50 / 150=0.033$ Euro 12

Benefiting for pass / $\mathrm{km}$ (bk) by reducing operating costs by DMU use is calculated as follow:

$b k=$ Co.bus. pass $/ \mathrm{km}-$ Co.DMU.pass $/ \mathrm{km}=0.075-0.033=0.035$ Euro per pass $/ \mathrm{km}$

While total profit for a year (Bk), for the total demand is calculated:

$$
B k=b k \cdot Q=0.035 \text { Euro per pass } / \mathrm{km} \cdot 57249451 \text { pass } / \mathrm{km}=2003730 \text { Euro }
$$

where:

$Q=$ total pass $/ \mathrm{km}$ demand.

\footnotetext{
12 The coefficient 40/30 shows the fuel litters consumption by train (figure 1) compared with consumption of a bus for around trip Tirana-Durres. The coefficient 50/150 shows the number of bus seats compared to the number of train seats (figure 1) Source of data's are the General Directorate of Albanian Railways and the author's observations.
} 


\section{Interchange train costs}

Exchange of passenger transport means within a trip is a violation of the comfort of travelling and therefore should be penalized. A train interchange causes passengers an average time of 5 minutes to move from one train to another and 10 minutes waiting to leave the train that will continue the journey. In the material presented the cost of travel will be increased as follow: the exchange time of train is penalized with 3 Euro per hour and the time waiting to leave 7 Euros per hour. ${ }^{13}$ Expected cost per passenger (ck) for the obligatory exchange of trains is:

$$
c k=\frac{t_{\text {weit }}}{60} \cdot V O T_{\text {weit }}+\frac{t_{\text {int }}}{60} \cdot V O T_{\text {journey }}=\frac{10 \cdot 7+5 \cdot 3}{60}=1,4 \quad \text { Euro/passenger }
$$

$$
\begin{array}{lll}
\text { Where: } & t_{\text {wait }} & \text { - waiting time } \\
& \text { tint } & - \text { interchange time } \\
& \text { VOT }_{\text {wait }} & \text { - value of waiting time } \\
& \text { VOT } & \text { - value of interchange time (travel) }
\end{array}
$$

Expected cost for one year (Ck) that the rail system could expect by the number of train users who are obliged to exchange on the train route is:

$$
C k=c k \cdot \text { Q.pass } \cdot f=1,4 \cdot 1541395 \cdot 0,048=103,582 \text { Euros }
$$

where:

Q.pass = total passengers number demand.

\section{Evaluation of travel time}

Travel time is a very important variable to influence the choice between train (DMU) and bus service. DMUs travel time in a refurbished rail axis Tirana-Durres, intended to be in the interval from 25 to 30 minutes. This requires a technical speed of the train on the rails of 100 kilometres per hour and exploitation speeds averaging 90 kilometres per hour. In addition to the departure and arrival station Durres and Tirana, the train will stop at Sukth and Vora stations. Compared to the actual travel time of buses, ranging in the interval 45 to 50 minutes, the travel time of DMU will be about 30 minutes or at least 15 minutes shorter. If we estimate the travel time 3 Euro per hour / traveller, it can be calculated the benefit of railway system from the smallest travel time compared to the bus system. One traveller benefit (bt) in one trip will be:

$$
b t=(T t-T b) \cdot \text { VOT journey }=(45-30) / 60 \times 3=0.75 \text { Euro/traveller }
$$

where:

$T t=$ train travel time in minutes

$T b=$ bus travel time in minutes

While the benefits of rail system (bt) for one year results:

\footnotetext{
${ }^{13}$ According to the model to consider (MAPRA 2010), the increased travel time of the trip caused by exchange of trains is penalized 6 Euro per hour/passenger and the waiting time for the train is 14 Euro per hour/passenger. For reasons of Albania's economic development level, in the material presented these values are halved respectively 3 and 7 Euros
} 


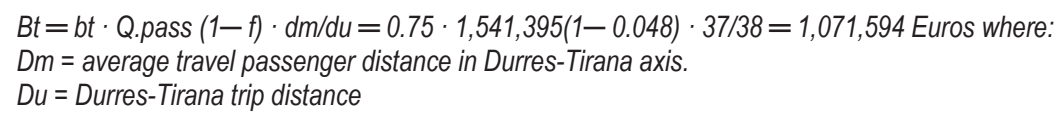

The travellers that exchange the train at Vora and Durres stations are exempted from the benefit of the evaluation of travel time in the Durres-Tirana axe.

\section{Moving commuters from car movement on road to railway}

Shifting commuters from using cars to railway is considered advantage for one more very important reason: the reduction of environmental pollution. Derived benefit for one traveller that gives up his car and travels from Tirana to Durres or vice versa by train is calculated as follow:

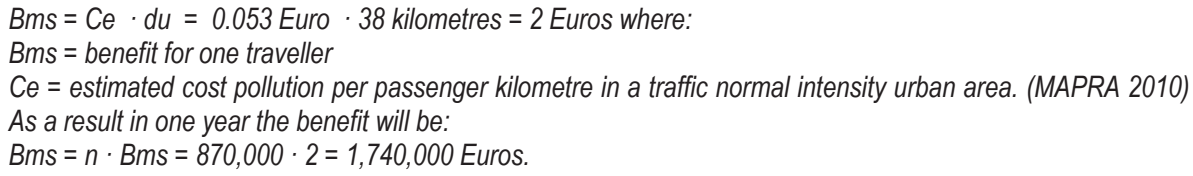

\section{Change of train service frequency in comparison to bus}

Because of the greater capacity, trains can meet the demand for transport service in this axis with a departures frequency lower than a bus. The bus carries a frequency of two departures per hour or every 30 minutes. The model provides one train at any hour, or every 60 minutes. In comparison with the 56 bus departures per day or 28 in each direction, the train will complete 28 departures per day or 14 in each direction. Reducing frequency brings an obligated increase of 30 minutes to the travel time for $50 \%$ of the total passenger demand. ${ }^{14}$ Costs that will add to rail transport by the frequency reduce cost is:

$$
\begin{aligned}
\text { C. freq } & =0.5 \cdot \text { Q.pass }(1-f) \cdot \text { T.freq } \cdot \text { VOT journey } \\
& =0.5 \cdot 1541395(1-0.048) \cdot 0.5 \cdot 3 \text { Euros }=1,100,556 \text { Euros }
\end{aligned}
$$

where:

$T$ freq $=$ Increase of the travel time due to reduced frequency

The travellers that exchange the train at Vora and Durres stations are exempted from the influence of the reduction departure frequency of the trains at the travel time in Tirana-Durres axis.

\section{Updating of overall costs and benefits and the net present value of choosing between train and bus}

The total updated costs of the introduced scheme to choice between train and bus is:

$$
C_{t o t}=I-R v+\int C_{m} e^{-r t} d t+\int C_{f} e^{(\theta-r) t} d t+\int C_{k} e^{(\theta-r) t} d t
$$

\footnotetext{
14 Sergio Jara-Diaz. Transport economic Theory. Elsevier, 2007, pp. 83 -88
} 


$$
\begin{aligned}
& =I-R v+C_{m} \int e^{-r t} d t+C_{f} \int e^{(\theta-r) t} d t+C_{k} \int e^{(\theta-r) t} d t \\
& =83180863-15129295+831808 \int e^{-r t} d t+1100556 \int e^{(\theta-r) t} d t+103582 \int e^{(\theta-r) t} d t \\
& =112,417,231 \text { Euros. }
\end{aligned}
$$

The total updated benefit of the introduced scheme to choice between train and bus will be:

$$
\begin{aligned}
& B_{\text {tot }}=\int\left[B_{m s}(Q)+B_{t}(Q)+B_{k}(Q)\right] e^{(\theta-r) t} d t \\
& =\int[1740000+1071594+2003730] e^{(\theta-r) t} d t \\
& =116,058,939 \text { Euros. }
\end{aligned}
$$

The net present value created by difference between benefits and costs in total is:

$$
N P V=\text { Btot }-C \text { tot }=116,058,939-112,417,231=3,641,708 \text { Euros }
$$

The net present value created by the comparison of the two exempted alternatives of the cost-benefit analysis model used determines an investment decision in favour of the rail system. The amount of the investment (I) allowed to be cast in favour of the railway choice is:

For net present value $=0$ the allowable investment $=94,438,466$ Euros

\section{DMUs and railway passenger service perspective in Albania}

Environmental pollution and roads blocking will not be an isolated problem on Durres-Tirana axis. The volume of road traffic in general, and especially in the middle part of the country, will increase in the coming years. The EU-15 Energy and Transport Outlook to 2030(European Commission DG Energy and transport 2003, p.61) forecast almost 50 percent growth in passenger transport and over 80 percent growth in freight in the EU-15 between 2000 and 2030. The majority of this merchandise will be transported by the road. It is predicted that by the year 203072.3 percent of passenger transport will be done by private owned cars and the average of EU citizen will be driving over 14,000 kilometres a year, compared with 10,000 in 2000.15 Albania still has a smaller number of cars in proportion to its population. To create a better idea we should stress the number of vehicles per 1000 inhabitants in some European countries: Italy has 690 vehicles per 1000 inhabitants according to the data of 2010; France has 578 vehicles according to the data of 2012; Spain has 608 vehicles according to the data of 2008; Germany has 634 vehicles according to the data of 2008; Croatia has 434 vehicles according to the data of 2009; Greece has 451 vehicles according to the data of 2008 and Albania has 141 vehicles according to the data of 2011. As per today Albania has a number of vehicles as much as 3 times less than Croatia and up to 4.9 times less than Italy. However, believing in its European future, this number will increase extensively in the coming years. 17

Road axes from Tirana to Lac and from Durres to Rrogozhina have begun to show overload problems, especially in the summer season. Therefore, problems discussed in Durres-Tirana axis will soon be experienced in the future in the other axes as well

Albanian railway network with a length of 440 kilometres runs mainly across the western plains, where is concentrated the larger part of the country's population. Actually railway covered limited areas and trains

15 Graham H. May. Transport in Europe: Where are we going? 2000 http://www.emeraldinsight.com/journals.htm?articleid=1529609\&show= 
circulate in short distances among urban centres, however, the use of DMUs can be expanded in the future. ${ }^{16}$ The study of establishing initially DMU service in specific segments and later spreading it out on wherever regions trains operate, it can guide the development of passenger transport towards a clear and well-defined future.

\section{References}

Alush Kuci; Asllan Haderi. "The light trains -the future of Albanian Railway". 3d international scientific conference, Aleksander Moisiu University, Durres, Albania, April, 8-9, 2011.

Addition to the study: National Transport Plan Number two. Lowis Berger. 2010. Source: Albanian Railway Directorate.

Data on the passenger railway transport service in Albania. (2011) General Directorate of Albanian Railway (Business unit passenger transport).

Data on the public passenger bus transport service between Tirana and Durres .Municipality of Durres. (Transport section)

Data related to the number of vehicles in Albania. Source: Ministry of the Transport and Telecommunication, Statistical sector.

Leonard Zisi, Liguria Roshi, Virgil Sallabanda, Chris Mara. Foto Zupa. Economics of Transport. Chapter Railway Transport. Dispatch Magazine printing presses. Tirana 1974.

Graham H. May. Transport in Europe: Where are we going? (2000)

http://www.emeraldinsight.com/journals.htm?articleid=1529609\&show=

Grimaldi, Raffaele; Laurino, Antonio and Beria, Paolo (2010): The choice between bus and light rail transit: a stylized costbenefit analysis model. DiAP - Politecnico di Milano, DiAP - Politecnico di Milano, DiAP - Politecnico di Milano 2010. Online at: http://mpra.ub.uni-muenchen.de/24872/1/MPRA_paper_24872.pdf MPRA Paper No. 24872, posted 09. September 2010 / 11:27

Luisa Affuso, Julien Masson, and David Newbery. Comparing Investment on new transport infrastructure. Roads vs. Railways? Department of Applied Economics, University of Cambridge, b. Ecole Politechnique. First Draft: November 2000. This draft: July 2003.

Robert H. Frank. The Darwin Economy, Liberty, Competition, and the Common Good. Princeton University Press ( Princeton and Oxford), Chapter 11, Taxing Harmful Activities, pp. 172 -183.

Sergio Jara-Diaz. Transport economic Theory. Elsevier, 2007, pp. 83-88.

Stuart Cole. Applied Transport Economics. Policy. Management \& Decision Making. Third Edition, Kogan Page. London and Steering Va. p. 164.

120 Pentonvile Road London NI 9JN United Kingdom . London and Stering Va. Chapter 6 Cost levels and structure Railway. Page 163 -182. Chapter 12. Funding an Integrated Transport Policy. Page 347 - 383.

Study of the Future Role of Albanian Railways (1995) CIE Consult, World Bank Albanian Railway Directorate.

${ }^{16}$ Alush Kuci, Asllan Haderi. "The light trains -the future of Albanian Railway". 3d international scientific conference, Aleksander Moisiu University, Durres, Albania, April, 8-9, 2011 
